\title{
Prevalence of Hysterectomy among Gynecological Surgeries in a Tertiary Care Hospital
}

\author{
Tara Manandhar, 'Sarita Sitaula,' Baburam Dixit Thapa,' Ajay Agrawal, ' Achala Thakur' \\ 'Department of Obstetrics and Gynecology, B. P. Koirala Institute of Health Sciences, Dharan, Nepal.
}

Introduction: Hysterectomy is the most common gynecological procedure. Over the last decade, the minimally invasive approach has been practiced more frequently. Fibroid uterus being the most common indication for hysterectomy justifies this minimal approach, however, whenever feasible, vaginal hysterectomy can be the preferred route. The objective of this study was to find out the prevalence and indication of hysterectomy among major gynecological surgeries in a tertiary care hospital.

Methods: A descriptive cross-sectional study was done at a tertiary care hospital among 1912 patients who had major gynecological surgeries from January 2017 to December 2019. Ethical clearance was obtained from the institutional review committee (ref. no. ACD 935/076/077). Convenient sampling was used. Statistical analysis was done using Statistical Package for Social Sciences version 21.0. Point estimate at $95 \%$ Confidence Interval was calculated along with frequency and proportion for binary data.

Results: During the study period, there were 1,912 major gynecological surgeries and the prevalence of hysterectomy was 1,131 (59.15\%) (56.94-61.35 at 95\% Confidence Interval). Fibroid uterus was the most common clinical indication for hysterectomy which was done in 397 (35.10\%) patients, followed by uterovaginal prolapse in 254 (22.46) patients, adnexal mass in 210 (18.56\%), and abnormal uterine bleeding in $117(10.34 \%)$ patients.

Conclusions: Hysterectomy, being the most common gynecological surgery, selection of the most appropriate route is of paramount importance. As for any other surgery, it is not without complication and hysterectomy should always be justified. With the advancement in the conservative approaches, these organ-preserving options should be explored rigorously before opting for hysterectomy.

Keywords: hysterectomy; laparoscopy; leiomyoma; pelvic organ prolapse.

\section{INTRODUCTION}

Hysterectomy is the most common surgery in Gynecology. Depending on nature of disease and patient's characteristics, it is performed via abdominal, vaginal or minimally invasive approach. ${ }^{1-4}$ the fourth National Family Health Survey (NFHS-4 Rate of a hysterectomy varies between the countries ranging from 2.13-3.62/1000 in Germany to 5.4/1000 in United States. ${ }^{5}$ Fibroid uterus, abnormal uterine bleeding (AUB), pelvic organ prolapse and benign ovarian tumours are common indications for hysterectomy. ${ }^{1,2,4-8}$
Abdominal hysterectomy is still the most commonly used approach. But, there have been preferences for vaginal and laparoscopic approaches recently. 4-6,9-12.

The uterus is an organ of self-being for women, so hysterectomy apart from its defined complications inherits great dissatisfaction for women. As per

\footnotetext{
Correspondence: Dr. Tara Manandhar, Department of Obstetrics and Gynecology, B. P. Koirala Institute of Health Sciences, Dharan, Nepal. Email: tara2073m@gmail.com, Phone: +977. 9845517690 .
} 
recommended by expert panel, $70 \%$ of hysterectomy were not appropriate. ${ }^{12}$ There have been improvements in the organ-preserving options especially for benign indication and these options should be explored..$^{5,13}$

This study aimed to find out the prevalence and indication of hysterectomy among gynaecological surgeries in a tertiary care center.

\section{METHODS}

A descriptive cross-sectional study was done at B.P Koirala Institute of Health Sciences, Dharan, Nepal, from January 2017 to December 2019. Ethical clearance was obtained from the institutional review committee (IRC Ref. No. ACD 935/076/077) before starting the study. All the patients who had undergone hysterectomy at BPKIHS during the study period were included in the study. Hysterectomy done outside and referred to BPKIHS for various other reasons, postpartum hysterectomy and emergency hysterectomy were excluded from the study. The convenient sampling technique was used. The sample size was calculated using the formula:

$$
\begin{aligned}
\mathrm{n} & =\mathrm{Z}^{2} \times \mathrm{p} \times(1-\mathrm{p}) / \mathrm{e}^{2} \\
& =(1.96)^{2} \times(0.5) \times(1-0.5) /(0.03)^{2} \\
& =1067.11 \\
& =1067 \\
& \text { Where, } \\
\mathrm{n} & =\text { required sample size } \\
\mathrm{Z} & =1.96 \text { at } 95 \% \text { Confidence Interval }(\mathrm{Cl}) \\
\mathrm{p} & =\text { population proportion, } 50 \% \\
\mathrm{e} & =\text { margin of error, } 3 \%
\end{aligned}
$$

Taking a $10 \%$ non-response rate, the sample size became 1174. However, 1912 patients were enrolled in the study.

The case records of all the patients were reviewed and the patients' demography, indications of surgery, surgical approach, complication, and mortality were noted. Abdominal hysterectomy included total abdominal hysterectomy (TAH), TAH with bilateral salpingectomy, bilateral salphing-oophorectomy (BSO), and radical hysterectomy, but these subgroups were analyzed separately. Apart from radical hysterectomy which was analyzed separately, the hysterectomy done as a part of staging laparotomy for malignancy was included in TAH. Minimal invasive hysterectomy included Laparoscopic-assisted vaginal hysterectomy (LAVH) and total laparoscopic hysterectomy (TLH). All the Histopathological diagnosis was noted and was compared with the preoperative diagnosis to see the accuracy and justify the need for hysterectomy. We used the Statistical Package for Social Sciences version 21.0 and point estimate at $95 \%$ Confidence interval was calculated along with frequency and proportion for binary data.

\section{RESULTS}

During the study period, there was a total of 1912 major gynecological surgeries, out of which 1131 (59.15\%) (56.94-61.35 at 95\% Cl) patients underwent a hysterectomy. Among 1131 hysterectomized patients, $1110(98.14 \%)$ patients underwent open and the rest $21(1.85 \%)$ had minimally invasive surgery. Abdominal hysterectomy was performed in 855 (75.59\%) patients

\begin{tabular}{|c|c|c|c|c|}
\hline \multirow{3}{*}{$\begin{array}{l}\text { Type of } \\
\text { Hysterectomy } \\
\text { Open }\end{array}$} & \multicolumn{3}{|l|}{ Year } & \multirow{3}{*}{$\begin{array}{l}\text { Frequency } \\
\mathrm{n}(\%)\end{array}$} \\
\hline & 2017 & 2018 & 2019 & \\
\hline & & & & \\
\hline $\begin{array}{l}\text { Radical } \\
\text { hysterectomy }\end{array}$ & 4 & 2 & 3 & $9(0.79)$ \\
\hline $\mathrm{TAH}^{*}$ & 13 & 1 & 1 & $15(1.32)$ \\
\hline $\begin{array}{l}\text { TAH + bilateral } \\
\text { salphingectomy }\end{array}$ & 25 & 85 & 42 & $152(13.43)$ \\
\hline TAH + BSO† & 211 & 243 & 225 & $679(60.03)$ \\
\hline VH + PFR & 83 & 86 & 86 & $255(22.54)$ \\
\hline \multicolumn{5}{|l|}{ Minimal Invasive } \\
\hline TLH & 7 & 6 & 5 & $18(1.59)$ \\
\hline LAVH§ & 1 & 1 & 1 & $3(0.26)$ \\
\hline Total & 344 & 424 & 363 & $1131(100)$ \\
\hline
\end{tabular}
and vaginal hysterectomy in 255 (22.54\%) patients. Minimal invasive surgery was done in 21 (1.85\%) patients. Out of 21 cases, 2 (9.52\%) Total Laparoscopic Hysterectomy required conversion to open. The type of surgical approach had remained constant in the last three years except for transabdominal hysterectomy (TAH) with bilateral salpingectomy which was high in the year 2018 (Table 1).

*TAH: total abdominal hysterectomy, †BSO: bilateral salphing-oophorectomy, $¥$ TLH: total laparoscopic hysterectomy, §LAVH: Laparoscopic-assisted vaginal hysterectomy.

Fibroid uterus was the most common clinical indication for hysterectomy which was done in 397 (35.10\%) patients, followed by uterovaginal prolapse in 254 (22.46) patients, adnexal mass in 210 (18.56\%), and abnormal uterine bleeding in 117 (10.34\%) patients. These four were the major 978 (86.47\%) indications for hysterectomy. There was a significant decrease in the cases of Adnexal mass and Pre-invasive disease in the year 2019, but the overall common disease pattern remains the same over the last three years (Table 2).

\begin{tabular}{|lllll|}
\hline \multicolumn{5}{|c|}{ Table 2. Indications for Hysterectomy. } \\
\hline Indication & Year & & & Frequency \\
& 2017 & 2018 & 2019 & $\mathrm{n}(\%)$ \\
Abdominopelvic & 13 & 13 & 23 & $49(4.33)$ \\
Mass & & & &
\end{tabular}


Manandhar, et al. Prevalence of Hysterectomy among Gynecological Surgeries in a Tertiary Care Hospital: A Descriptive...

\begin{tabular}{|lllll|} 
Adnexal Mass & 71 & 87 & 52 & $210(18.56)$ \\
Adenomyosis & 10 & 12 & 11 & $33(2.92)$ \\
\hline $\begin{array}{l}\text { Abnormal uterine } \\
\text { bleeding with } \\
\text { Failed Medical } \\
\text { Management }\end{array}$ & 30 & 40 & 47 & $117(10.34)$ \\
$\begin{array}{l}\text { Endometrial } \\
\text { Polyp }\end{array}$ & 0 & 0 & 1 & $1(0.09)$ \\
$\begin{array}{l}\text { Pyometra } \\
\text { Fibroid }\end{array}$ & 2 & 1 & 1 & $4(0.35)$ \\
$\begin{array}{l}\text { Cervical Fibroid } \\
\text { Fibroid Uterus } \\
\text { Uterovaginal }\end{array}$ & 1 & 0 & 0 & $1(0.09)$ \\
$\begin{array}{l}\text { Prolapse } \\
\text { Pre-invasive }\end{array}$ & 82 & 86 & 86 & $254(22.46)$ \\
$\begin{array}{l}\text { Disease } \\
\text { Malignancy }\end{array}$ & 11 & 19 & 4 & $33(2.92)$ \\
Total & 344 & 424 & 363 & $1131(100)$ \\
\hline
\end{tabular}

Complications were seen among 40 (3.53\%) patients who underwent major gynecological surgeries. Twenty-one patients had an iatrogenic injury during surgery: bowel injury in $15(1.3 \%)$, bladder in $5(0.4 \%)$, and $1(0.09 \%)$ had a major vascular injury. In the 15 patients who had bowel injury, 13 patients underwent primary repair and had an uneventful recovery. One patient had a sigmoid injury requiring colostomy and in another patient, ileal perforation was detected on the 2nd postoperative day, requiring laparotomy and ileostomy. Both of these patients had successful restoration of the bowel continuity. All the bladder injuries were detected intraoperatively and repaired with an uneventful outcome. Fourteen patients $(1.24 \%)$ had surgical site infection and three $(0.27 \%)$ patients had a postoperative chest infection. We had two $(0.17 \%)$ mortality. One patient who had a ruptured dermoid cyst developed postoperative septicemia and another one operated on for carcinoma ovary died due to chest infection (Table 3).

\begin{tabular}{|ll|}
\hline $\begin{array}{l}\text { Table 3. Intraoperative and postoperative } \\
\text { complications. }\end{array}$ \\
\hline Variables & Frequency n (\%) \\
Intraoperative & $15(1.32)$ \\
Bowel injury & $5(0.44)$ \\
Bladder injury & $1(0.09)$ \\
Major vascular injury & $81.5 \pm 37.51$ \\
Operative time (mean \pm SD) & \\
Postoperative & 3 \\
Hospital stay (median days) & $14(1.24)$ \\
Wound infection & $3(0.27)$ \\
Chest infection & $2(0.17)$ \\
Mortality & \\
\hline
\end{tabular}

Similarly, the histopathological examination of the specimen was done to confirm the diagnosis. The histopathological analysis of the specimens revealed leiomyoma $450(39.79 \%)$ as the most common finding. There were $189(16.73 \%)$ cases of the benign tuboovarian disease in which mature cystic teratoma 91 (48.15\%) was the commonest finding. Fifty-one (4.5\%) patients had malignancy and ovarian carcinoma $22(43.1 \%)$ was the commonest malignant disease. Mature cystic teratoma was the most common cause for both abdominopelvic mass 12 (24.49\%) and adnexal mass 76 (36.19\%). Yearly analysis of histopathological diagnosis revealed the drop in the cases of Endometriosis and pre-invasive disease in the year 2019. Table 4 shows the histopathological diagnosis of the specimen in the study duration from 2017 to 2019 (Table 4).

\begin{tabular}{|c|c|c|c|c|}
\hline \multicolumn{5}{|c|}{$\begin{array}{l}\text { Table 4. Histopathological diagnosis of the } \\
\text { specimen. }\end{array}$} \\
\hline Histopathological & Year & & & Frequency \\
\hline Diagnosis & 2017 & 2018 & 2019 & n (\%) \\
\hline Adenomyosis & 28 & 33 & 37 & $98(8.66)$ \\
\hline Endometriosis & 11 & 26 & 5 & $42(3.71)$ \\
\hline Endometritis & 3 & 1 & 6 & $10(0.88)$ \\
\hline $\begin{array}{l}\text { Endometrial } \\
\text { Polyp }\end{array}$ & 2 & 1 & 3 & $6(0.53)$ \\
\hline Leiomyoma & 129 & 178 & 143 & 450 (39.79) \\
\hline Lipoma Uterus & 1 & 0 & 0 & $1(0.09)$ \\
\hline Pyometra & 0 & 0 & 1 & $1(0.09)$ \\
\hline Chronic Cervicitis & 82 & 84 & 87 & 253 (22.37) \\
\hline $\begin{array}{l}\text { Tubo-ovarian } \\
\text { disease (benign) }\end{array}$ & 63 & 62 & 64 & $189(16.71)$ \\
\hline $\begin{array}{l}\text { Mature Cystic } \\
\text { Teratoma }\end{array}$ & 31 & 30 & 30 & $91(48.15)$ \\
\hline $\begin{array}{l}\text { Serous } \\
\text { Cystadenoma }\end{array}$ & 13 & 9 & 7 & $29(15.34)$ \\
\hline Hemorrhagic Cyst & 9 & 6 & 13 & $28(14.81)$ \\
\hline $\begin{array}{l}\text { Mucinous } \\
\text { Cystadenoma }\end{array}$ & 4 & 4 & 3 & $11(5.82)$ \\
\hline Paratubal Cyst & 3 & 5 & 3 & $11(5.82)$ \\
\hline Others & 3 & 8 & 8 & $19(10.05)$ \\
\hline $\begin{array}{l}\text { Pre-invasive } \\
\text { disease }\end{array}$ & 8 & 14 & 1 & $23(2.03)$ \\
\hline Borderline & 1 & 3 & 3 & $7(0.62)$ \\
\hline Malignancy & 16 & 22 & 13 & $51(4.51)$ \\
\hline Uterus & 2 & 3 & 6 & $11(21.57)$ \\
\hline Ovary & 8 & 11 & 3 & $22(43.14)$ \\
\hline $\begin{array}{l}\text { High Grade } \\
\text { Serous } \\
\text { Carcinoma }\end{array}$ & 6 & 7 & 1 & 14 \\
\hline Others & 2 & 4 & 2 & 8 \\
\hline Cervix & 5 & 7 & 4 & $16(31.37)$ \\
\hline $\begin{array}{l}\text { Squamous Cell } \\
\text { Carcinoma }\end{array}$ & 5 & 6 & 3 & 14 \\
\hline Others & 0 & 1 & 1 & 2 \\
\hline $\begin{array}{l}\text { Metastatic } \\
\text { Adenocarcinoma }\end{array}$ & 1 & 1 & 0 & 2 (3.92) \\
\hline
\end{tabular}


Manandhar, et al. Prevalence of Hysterectomy among Gynecological Surgeries in a Tertiary Care Hospital: A Descriptive...

|Total $\quad 344 \quad 424 \quad 363 \quad 1131$

The mean age of the patients undergoing hysterectomy was $49.35 \pm 10.30$ years (range 26 to 86 years) and $471(41.64 \%)$ hysterectomy was done in the age group between 41-50 years. (Table 5)

\begin{tabular}{|ll|}
\hline \multicolumn{2}{|l|}{ Table 5. Demographic profile of the patients } \\
undergoing hysterectomy. & \\
\hline Variables & Frequency $\mathrm{n}(\%)$ \\
Age Group & \\
$\leq 30$ & $8(0.70)$ \\
$31-40$ & $230(20.33)$ \\
$41-50$ & $471(41.64)$ \\
$51-60$ & $248(21.92)$ \\
$61-70$ & $128(11.31)$ \\
$71-80$ & $40(3.53)$ \\
$81-90$ & $6(0.53)$ \\
Parity & \\
Nulligravida & $64(5.65)$ \\
P1-P5 & $939(83.02)$ \\
$>$ P5 & $138(12.20)$ \\
Comorbid conditions & \\
Hypertension & $121(10.69)$ \\
Diabetes & $54(4.77)$ \\
Hypothyroidism & $43(3.80)$ \\
Respiratory disease & $23(2.03)$ \\
Others & $21(1.85)$ \\
\hline
\end{tabular}

\section{DISCUSSION}

Hysterectomy was the most common (59.15\%) gynecological surgery performed in our institute. A total of $62.68 \%$ hysterectomies were performed in the patients aged less than 51 years, which is the common age for hysterectomy as reported by Morgan et al, where they had $78.3 \%(n=302,547)$ hysterectomy in patient age less than 55 years. ${ }^{1}$ There seems to be a decreasing trend in hysterectomy in the reproductive age group women in the USA, and also an overall decline in the rate of hysterectomy $(36.4 \%$ decline from 2002 to 2010), but we had no significant change in the rate of hysterectomy in last three years and was highest in the year 2018 (37.4\%)..$^{1,14}$

The most common indication for hysterectomy was the fibroid uterus followed by pelvic organ prolapse, adnexal mass, and AUB. These four were the major indication for hysterectomy (86.47\%) in our study. Fibroid uterus remains the most common indication for elective hysterectomy worldwide, constituting 39.9 to $73.7 \%$ of all hysterectomy..$^{3-5}$ The incidence of pelvic organ prolapse is decreasing in developed countries, but it is still the second most common indication and constitute a major bulk for hysterectomy $(16.3 \%$ $-18.83 \%$ ) in developing countries. ${ }^{1,4,14,15}$ This trend was also similar in our study (pelvic organ prolapse $=22.46 \%$ ), whereas Toma et al. from Canada had
DUB (26.4\%) as the most common indication for hysterectomy followed by leiomyoma uterus $(16 \%){ }^{7}$

Over the past decade, there has been a steadily increasing use of minimally invasive gynecological surgery: $3-15.5 \%$ in $2002-2006$ to $36-43.4 \%$ in 2012 $-2013.1,10,14$ We have seen progress in laparoscopic surgery in our institute as well. From 2002 to 2018, there was 4 fold increase in laparoscopic procedure in our institute, however, total cases of hysterectomies were low $(\mathrm{TLH}=7.7 \%, \operatorname{LAVH}=3 \%) .{ }^{16}$ In the last three years, we had 21 cases of minimally invasive hysterectomy $(1.8 \%$ of total hysterectomy), similar to the other part of the developing countries. ${ }^{4,15}$ This low rate may be explained by the low resources, the cost factor, and expertise available, in the government hospital of rural areas. If we can overcome this hurdle, there is a great place for laparoscopic hysterectomy, as seen in the study by Karki et al, where he reported 1012 cases of TLH in two years, from a private institute in eastern Nepal. ${ }^{17}$ This disparity was also seen in the study from Finland $(n=10,110)$ where the rate of Laparoscopic hysterectomy was high in a private hospital ( $\mathrm{LH}=67 \%$ ) compared to the local hospital (LH 19\%). ${ }^{6}$ Abdominal hysterectomy remains the common route ranging from $47.8 \%$ to $83.6 \%$. $^{10,18,19}$ Abdominal hysterectomy was also the commonest route in our study $(75.59 \%)$, and the rate was higher as compared with others because of the low incidence of minimally invasive hysterectomy. 1,18,20 However, this rate of abdominal hysterectomy was comparable to the studies $(70.2 \%-83.6 \%)$ where the laparoscopic approach was not or minimally used. , $^{3,4,719,21}$ Vaginal hysterectomy is the most recommended and preferred route whenever feasible, with the least morbidity and better outcomes. ${ }^{11,13} \mathrm{VH}$ is mostly performed for pelvic organ prolapse and was true in our study as well where we performed $\mathrm{VH}$ exclusively for pelvic organ prolapse only (99.6\%).3.4 With the proper patient selection, Kovac et al performed $\mathrm{VH}$ in $98.9 \%(10,975$ out of $11,094)$ patients with benign pathology, suggesting that abdominal and laparoscopic route might have been overused or misused. . $^{9,10}$

In our study, the total complication rate was $3.53 \%$ which was lower than the study from Finland $(n=10,110)$, where their complication rate was $17.1 \%$ - $23.3 \%$ but they had a significant decline in overall complication rate over 10 years $117.5 \%$ in 1996 to $14.7 \%$ in 2006). ${ }^{6,10}$ Whereas in the study from India, the overall complication rate was $8.5 \%$, with a significantly higher complication rate in the abdominal approach (10.9\% vs $2.1 \%$ in vaginal approach) ${ }^{4}$ Injury to urinary tract was most commonly seen during hysterectomy than in other major gynecological surgery and had been reported in 0.2 to $1.1 \%$ cases and was higher in laparoscopic hysterectomy, whereas the bowel injury 
has been reported to range from 0.1 to $1 \% .6,{ }^{10,18}$ The rate of organ injury in our study was comparable to these study groups. In the 15 patients who had bowel injury, 14 were detected intraoperatively. All the bladder injuries were detected intraoperatively and repaired with an uneventful outcome, similar to the study by Makinen et al where they detected $60-70 \%$ of organ injuries intraoperatively. ${ }^{10} 0.1 \%$ had external iliac artery injury requiring massive blood transfusion. This rate of vascular injury is also low in our study compared to the reported incidence of $2.1-3.1 \%{ }^{6}$

The reported incidence of surgical site infection after hysterectomy ranges from $0 \%$ to as high as $22.6 \% .18$ We had $1.24 \%$ patients who developed surgical site infection: superficial SSI (9), deep SSI (4), and organ-specific (1). Three patients $(0.26 \%)$ developed a postoperative chest infection. This rate of chest infection is comparable to other studies (0-2.16\%). ${ }^{18}$ In the study by Makinen et al, out of 10,110 hysterectomies, they had a mortality rate of $0.02 \%, 0.04 \%$, and $0.06 \%$ in abdominal, laparoscopic, and vaginal hysterectomy respectively. Surprisingly, their mortality rate was comparatively high for vaginal hysterectomy, which is supposed to have a low rate of morbidity. ${ }^{6}$ We had $0.17 \%$ mortality. One patient who had a ruptured dermoid cyst developed sepsis postoperatively and collapsed on the 7th postoperative day. Another patient who was operated on for carcinoma ovary was expired on the $10^{\text {th }}$ postoperative day because of postoperative chest infection.

The uterus is an organ of self-being for a female, so hysterectomy besides its procedure-related complications is a cause for dissatisfaction. In the study from the US regarding the appropriateness of hysterectomy, they found that at high as $70 \%$ of cases didn't meet the expert panel's criteria for the need for hysterectomy. ${ }^{12}$ We believe that hysterectomy was justified in $91.39 \%$ of our cases, after correlating with histopathological diagnosis, similar to other studies (84 -91.37\%).4,15 In $2.47 \%$ patients, we could have avoided hysterectomy as the specimen examination didn't reveal any significant pathology. Alternative treatment options like myomectomy, fibroid embolization, endometrial ablation, hysteroscopy with D\&C, polypectomy, or uterine artery embolization should always be considered depending on the disease and facility available, to avoid the inappropriate hysterectomy. ${ }^{5,22}$

\section{CONCLUSIONS}

Hysterectomy, being the most common gynecological surgery, selection of the most appropriate route is of paramount importance. As for any other surgery, it is not without complication and hysterectomy should always be justified. With the advancement in the conservative approaches, these organ-preserving options should be explored rigorously before opting for hysterectomy, keeping it as the last resort surgery.

\section{Conflict of Interest: None.}

\section{REFERENCES}

1. Morgan DM, Kamdar NS, Swenson CW, Kobernik EK, Sammarco AG, Nallamothu B. Nationwide trends in the utilization of and payments for hysterectomy in the United States among commercially insured women. Am J Obstet Gynecol. 2018 Apr;218(4):425.e1-425.e18. [P $\underline{\text { PubMed | Full }}$ $\underline{\text { Text }} \mid \underline{\mathrm{DOI}}]$

2. Shekhar C, Paswan B, Singh A. Prevalence, sociodemographic determinants and self-reported reasons for hysterectomy in India. Reprod Health. 2019;16(1):1-16. [PubMed | Full Text | $\underline{\mathrm{DOI}}]$

3. Leung PL, Tsang SW, Yuen PM; Quality Assurance Subcommittee in Obstetrics and Gynaecology, Hospital Authority, Hong Kong. An audit on hysterectomy for benign diseases in public hospitals in Hong Kong. Hong Kong Med J. 2007 Jun;13(3):187-93. [ubMed | Full Text]

4. Pandey D, Sehgal K, Saxena A, Hebbar S, Nambiar J, Bhat RG. An Audit of Indications, Complications, and Justification of Hysterectomies at a Teaching Hospital in India. Int J Reprod Med. 2014;2014:1-6. [Full Text | DOI]

5. Neis KJ, Zubke W, Fehr M, Römer T, Tamussino K, Nothacker
M. Hysterectomy for Benign Uterine Disease. Dtsch Arztebl Int. 2016;113(14):242-9. [PubMed | Full Text | DOI]

6. Makinen J. Morbidity of 10110 hysterectomies by type of approach. Hum Reprod. 2001;16(7):1473-8. [ Full Text | DOI]

7. Toma A, Hopman WM, Gorwill RH. Hysterectomy at a Canadian tertiary care facility: Results of a one year retrospective review. BMC Womens Health. 2004;4:2-8. [PubMed | Full Text | DOI]

8. Lykke R, Blaakær J, Ottesen B, Gimbel H. The indication for hysterectomy as a risk factor for subsequent pelvic organ prolapse repair. Int Urogynecol J. 2015;26(11):1661-5. [PubMed $\mid$ Full Text $\mid \underline{\text { DOI }}$

9. Kovac S R. 28 Years of Using Hysterectomy Guidelines to Determine the Feasibility of Vaginal Hysterectomy. Gynecol Obstet. 2015;06(04). [Full Text | DOI]

10. Mäkinen J, Brummer T, Jalkanen J, Heikkinen A-M, Fraser J, Tomás E, et al. Ten years of progress--improved hysterectomy outcomes in Finland 1996--2006: a longitudinal observation study. BMJ Open. 2013 Oct;3(10):e003169. [라Med | Full Text $\mid$ DOI] 
11. Sandberg EM, Hehenkamp WJK, Geomini PM, Janssen PF, Jansen FW, Twijnstra ARH. Laparoscopic hysterectomy for benign indications: clinical practice guideline. Arch Gynecol Obstet. 2017;296(3):597-606. [PubMed | Full Text | DOI]

12. Broder MS, Kanouse DE, Mittman BS, Bernstein SJ. The appropriateness of recommendations for hysterectomy. Obstet Gynecol. 2000;95(2):199-205. [PubMed | Full Text | DOI]

13. Committee on Gynecologic Practice. Committee Opinion No 701: Choosing the Route of Hysterectomy for Benign Disease. Obstet Gynecol. 2017;129(6):e155-e159. [라Med | $\underline{\text { Full Text }}$ | DOI]

14. Wright JD, Herzog TJ, Tsui J, Ananth C V., Lewin SN, Lu YS, et al. Nationwide trends in the performance of inpatient hysterectomy in the United States. Obstet Gynecol. 2013;122(2 Pt 1):233-41. [PubMed | Full Text | DOI]

15. Vaidya S, Vaidya SA. Patterns of lesions in hysterectomy specimens in a tertiary care hospital. J Nepal Med Assoc. 2015;53(197):18-23. [PubMed | Full Text | DOI]

16. Agrawal A, Chandra Regmi MCR, Rijal P, Thakur A, Basnet $\mathrm{P}$. An experience of gynaecological laparoscopic surgeries at low resource setting. Birat J Heal Sci. 2020;4(3):796-800. [․ㅡll Text $\mid \underline{D O I}]$
17. Karki GMS, Neupane B, Regmi M, Shrestha R, Gupta S. Vaginal Cuff Dehiscence after Hysterectomy and One Minute Technique of Laparoscopic Vault Closure. Nepal J Obstet Gynaecol. 2017 Jun 3;11(2):8-11. [Full Text | DOI]

18. Clarke-Pearson DL, Geller EJ. Complications of Hysterectomy. Obstet Gynecol. 2013 Mar;121(3):654-73. [PubMed | Full Text | DOI]

19. Wiser $A$, Holcroft $C A$, Tulandi $T$, Abenhaim HA. Abdominal versus laparoscopic hysterectomies for benign diseases: Evaluation of morbidity and mortality among 465,798 cases. Gynecol Surg. 2013;10(2):117-22. [Full Text | DOI]

20. Driessen SRC, Baden NLM, van Zwet EW, Twijnstra ARH, Jansen FW. Trends in the Implementation of Advanced Minimally Invasive Gynecologic Surgical Procedures in The Netherlands. J Minim Invasive Gynecol. 2015 May;22(4):642-7. [PubMed | Full Text | DOI]

21. Liu F, Pan Y, Liang Y, Zhang C, Deng Q, Li X, et al. The epidemiological profile of hysterectomy in rural Chinese women: A population-based study. BMJ Open. 2017;7(6):1-9. [PubMed | Full Text | DOI]

22. American College of Obstetricians and Gynecologists. ACOG committee opinion no. 557: Management of acute abnormal uterine bleeding in nonpregnant reproductive-aged women.

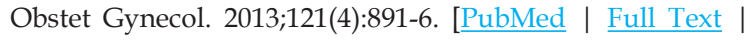
DOI] 